\title{
EL SISTEMA FISCAL Y LAS RENTAS DE LA HACIENDA MUNICIPAL DE PETRER EN EL SIGLO XVII
}

\author{
Tomás V. PÉREZ MEDINA
}

Petrer es una villa baronal valenciana con una población no superior al millar de habitantes durante el siglo XVII, cuyo señor feudal es el conde de Elda, de la familia de los Coloma y Pérez de Calvillo. La hacienda de las pequeñas villas y lugares señoriales contrasta con las finanzas estudiadas de las grandes ciudades forales. Por un lado, en las ciudades existe una oligarquía urbana que acapara el control de la actividad económica municipal a través del arrendamiento de monopolios y abastecimientos, que prima sus intereses en la gestión hacendística y controla mediante la insaculación el acceso a los cargos políticos ${ }^{2}$. En segundo lugar, la mayoría de las ciudades son de realengo y la expulsión de la comunidad morisca no les afecta tan notoriamente como a muchos pequeños lugares, entre los cuales se encuentra Petrer. Ser lugar de señorío baronal y de predominio morisco era argüído por la nobleza titular de tales comunidades para ver en el decreto de expulsión firmado por Felipe III un problema añadido a la gestión de sus casas nobiliarias: el endeudamiento censalista de las aljamas moriscas retraerá, indicaban, a los inmigrantes cristianos ${ }^{3}$.

Una de las funciones de los nuevos oficiales locales es atender y gestionar las fuentes de ingresos de la hacienda local. A este aspecto vamos a dedicar las páginas que siguen. Para atender las prestaciones señoriales y las exacciones estatales, para cubrir los salarios, las reparaciones de instalaciones comunitarias y los intereses de los créditos adquiridos, el municipio recurre a variados recursos financieros. Los procedimientos de la clavería local serán orientados bien a la explotación de propios y regalías, a la organización de un sistema fiscal basado en diferentes figuras impositivas directas y sobre el consumo o al crédito público para subvenir necesidades municipales. 
TABLA I.

Rentas e ingresos reales de la clavería de Petrer (en libras).

\begin{tabular}{|l|l|l|l|l|l|l|l||}
\cline { 2 - 8 } \multicolumn{1}{l|}{} & Propios & Regalías & $\begin{array}{l}\text { Impuestos } \\
\text { Directos }\end{array}$ & $\begin{array}{l}\text { Impuestos } \\
\text { Indirectos }\end{array}$ & Créditos & Alcances & TOTAL \\
\hline 1613 & 12 & & & 189 & & & 201 \\
\hline 1620 & 5 & 230 & 259 & 268 & 181 & & 943 \\
\hline 1627 & & 158 & 230 & 149 & & & 537 \\
\hline 1634 & & 289 & 70 & 107 & & & 466 \\
\hline 1641 & 43 & 134 & 341 & 78 & & & 596 \\
\hline 1648 & 25 & 154 & 241 & 123 & 570 & 10 & 1123 \\
\hline 1654 & 2 & 211 & & 217 & & & 430 \\
\hline 1662 & & 210 & 207 & 159 & & & 576 \\
\hline 1669 & & 176 & 326 & 124 & & 61 & 687 \\
\hline 1676 & & 171 & 377 & 186 & 80 & & 814 \\
\hline 1683 & & 233 & 465 & 131 & 25 & 230 & 1084 \\
\hline 1690 & 5 & 112 & 454 & 147 & 25 & 9 & 752 \\
\hline 1696 & 1 & 182 & 435 & 139 & 99 & 102 & 958 \\
\hline
\end{tabular}

Fuente: AMP: Llibres de Clavería, 52/1 a 52/6.

Elaboración propia.

La Tabla I nos presenta los capítulos de las finanzas que gestiona el clavario de Petrer. En la página siguiente hay un análisis detallado de cada tipo de rentas y de los mecanismos recaudatorios, pero una observación global de la mencionada tabla nos resalta el valor de la fiscalidad en la hacienda local. Si por fiscalidad entendemos la acción fiscal de las estructuras políticas sobre personas, consumos, rentas o patrimonios, en sus diferentes formas y métodos impositivos, para recabar rentas dirigidas a cubrir los gastos colectivos, este capítulo es el que primará en Petrer. En torno al $60 \%$ de las rentas de la hacienda local provienen de diferentes figuras fiscales, predominando progresivamente durante el s. XVII la imposición directa más que la aplicada al consumo. Los propios son casi inexistentes y las regalías mantienen unos valores similares durante la centuria. 
El recurso al crédito, temporal o perpétuo, dependerá tanto del nivel del gasto local como de la flexibilidad recaudatoria de regalías e imposiciones fiscales. La Tabla II recoge las rentas teóricas y su comparación con los gastos téoricos totales. Durante la segunda mitad del s. XVII el recurso al crédito tratará de equilibrar la negativa balanza presupuestaria. Este endeudamiento repercutirá, a su vez, en un aumento de la fiscalidad directa sobre el vecindario.

TABLA II.

Comparación de las rentas teóricas y de los gastos teóricos de la hacienda municipal de Petrer (en libras).

\begin{tabular}{||l|l|l|l|l|l|l|l||}
\hline Año & Propios & Regalías & $\begin{array}{l}\text { Impuestos } \\
\text { Directos }\end{array}$ & $\begin{array}{l}\text { Impuestos } \\
\text { Indirectos }\end{array}$ & $\begin{array}{l}\text { Total } \\
\text { Ingresos }\end{array}$ & $\begin{array}{l}\text { Total } \\
\text { Gastos }\end{array}$ & $\begin{array}{l}\text { Dife- } \\
\text { rencia }\end{array}$ \\
\hline 1620 & 10 & 183 & 240 & 151 & 584 & 514 & +70 \\
\hline 1648 & 10 & 177 & 243 & 156 & 586 & 697 & -111 \\
\hline 1669 & 10 & 156 & 336 & 142 & 644 & 727 & -83 \\
\hline 1696 & 10 & 178 & 474 & 158 & 820 & 952 & -132 \\
\hline
\end{tabular}

Elaboración propia.

\section{Rentas municipales de propios y regalías}

En este apartado se reunen dos fuentes de ingresos que se caracterizan por la ausencia de cualquier tipo de imposición fiscal sobre la población. Los propios son aquellos bienes patrimoniales del municipio que permiten a la clavería local obtener ingresos sin gravar a los habitantes de la villa. El Consell General y el Consell Particular, en cuanto instituciones políticas con carácter jurídico, son poseedores de cualquier tipo de bienes. En unos casos hay propios que son utilizados comunitariamente y no producen una rentabilidad financiera perceptible en la tesorería municipal; es la situación de los edificios públicos como la lonja, la casa de la vila, la balsa, el lavadero, la font de la plaça... Pero en otros casos hay propiedades que sí repercuten en entradas de la clavería al ser arrendadas para su uso y explotación a individuos particulares a cambio de una renta (se arriendan casas y tierras municipales y se venden las aguas sobrantes de la balsa de riego).

Es decir, estos bienes patrimoniales de la villa aportan ingresos a la clavería municipal sin gravar a los habitantes. Pero los propios de la villa de Petrer son escasos y es una fuente de ingresos prácticamente nula en el s. XVII. Los sobrantes del aygua de la baça subastados y vendidos, - como por ejemplo la "basada de aygua que es vene a Arnau Barlonguera en lo mes de agost de l696" por 1 libra 4 
sueldos ${ }^{4}$ - y las casas y tierras propiedad de la villa arrendadas, como son "los bancalets de la Vila nomenats de la Comare" ${ }^{\prime 5}$, reportan cantidades inferiores al 5 $\%^{6}$.

Las regalías comprenden una serie de establecimientos y derechos que se reserva el señor feudal por su poder jurisdiccional sobre el señorío: hornos, molinos, tienda, panadería, taberna, herbaje, Asegurada de la farina ... Progresivamente, durante el s. XVII el conde de Elda transfiere al municipio la explotación de algunas regalías, que no el privilegio de posesión, a cambio de una renta anual fija. De este modo, estos monopolios y regalías son administrados por los jurados locales cual propios municipales, pero no pueden ser calificados de este modo por la reserva que hace el señor feudal del privilegio y derecho de posesión y por la renta que le paga la villa. Los jurados arrendarán la explotación a particulares a cambio de un precio que será ingresado en la clavería local. De este modo, las regalías, aunque formalmente no son arbitirios indirectos, se tornan impuestos sobre el consumo al trasladar los arrendatarios sus costes sobre el precio de los productos y servicios ${ }^{7}$.

En la Tabla III aparecen los ingresos reales por propios y regalías de la hacienda de Petrer. Entre los monopolios destaca la tienda, uno de los principales establecimientos para el abastecimiento de la comunidad rural. La tienda es cedida al municipio para que éste la administre y explote, percibiendo el colector condal una renta permamente de 40 libras anuales. Los jurados arrendarán en pública subasta la tienda a un particular. La generación de recursos financieros a partir de este establecimiento se observa en la Tabla IV, donde el precio anual del arriendo sigue una línea ascendente durante el s. XVII. El abastecimiento alimenticio a una población en crecimiento hace que esta regalía se revalorice.

La taberna y la panadería son dos establecimientos locales que, a cambio de una renta anual conjunta de 40 libras pagadas al conde de Elda, gestionará la villa mediante arrendamientos. El arrendatario se compromete a expender pan diariamente y a tener abastecida la taverna del vi. Extrañamente, estos dos establecimientos siguen una línea inversa a la curva demográfica, pues durante la segunda mitad del s. XVII la hacienda municipal anualmente pierde dinero con ellos. Desconocemos los motivos exactos del descenso de la renta de la taberna y panadería en la segunda mitad del s. XVII, justo en un momento de aumento de la producción vinícola y su autoconsumo por los vecinos de la comunidad rural y la expedición de pan y mayor uso vecinal de los hornos, influyen en la bajada del valor de la panadería y la taberna ${ }^{8}$. 
TABLA III.

Ingresos reales de la clavería de Petrer

por propios y regalías (en libras).

\begin{tabular}{|c|c|c|c|c|c|c|c|}
\hline Año & $\begin{array}{l}\text { Agua, } \\
\text { Casas, } \\
\text { Tierras }\end{array}$ & $\begin{array}{l}\text { Hebaje } \\
\text { y } \\
\text { Bovalar }\end{array}$ & $\begin{array}{l}\text { Asegura } \\
\text { de la } \\
\text { Harina }\end{array}$ & $\begin{array}{l}\text { Hornos } \\
\text { y } \\
\text { Molinos }\end{array}$ & $\begin{array}{l}\text { Taberna y } \\
\text { Panadería }\end{array}$ & Tienda & TOTAL \\
\hline 1613 & 12 & & & & & & 12 \\
\hline 1620 & 5 & 71 & & & 71 & 88 & 235 \\
\hline 1627 & & 65 & & & 40 & 53 & 158 \\
\hline 1634 & & 24 & & 165 & 50 & 50 & 289 \\
\hline 1641 & 43 & & 1 & & 29 & 106 & 179 \\
\hline 1648 & 25 & & 4 & & 94 & 126 & 249 \\
\hline 1654 & 2 & & 2 & & 75 & 134 & 213 \\
\hline 1662 & & 39 & & & 40 & 131 & 210 \\
\hline 1669 & & 31 & 10 & & 36 & 99 & 176 \\
\hline 1676 & & 38 & 4 & & 34 & 95 & 171 \\
\hline 1683 & & 46 & 15 & & 44 & 128 & 233 \\
\hline 1690 & 5 & 33 & 9 & & 17 & 53 & 117 \\
\hline 1696 & 1 & 50 & 16 & & 16 & 100 & 183 \\
\hline
\end{tabular}

Fuente: AMP: Llibres de Clavería, 52/1 a 52/6. AMP: Llibres de Consells, 49/1 a 49/2. Elaboración propia. 
TABLA IV.

Precios del arrendamiento anual de la tienda, taberna y panadería de Petrer (en libras).

\begin{tabular}{|c|c|c|c|c|c|}
\hline Aก̃o & Vecinos & Tienda & Sueldos/Vecino & $\begin{array}{l}\text { Taberna y } \\
\text { Panadería }\end{array}$ & Sueldos/Vecino \\
\hline 1620 & & 54 & & 59 & \\
\hline 1621 & $\begin{array}{c}141 \\
(1624)\end{array}$ & 70 & $9-11$ & 70 & $9-11$ \\
\hline 1627 & & 49 & & 39 & \\
\hline 1628 & & 54 & & 50 & \\
\hline 1634 & $\begin{array}{c}133 \\
(1633)\end{array}$ & 50 & $7-6$ & 50 & $7-6$ \\
\hline 1641 & & 81 & & 70 & \\
\hline 1648 & & 60 & & 58 & \\
\hline 1649 & $\begin{array}{c}137 \\
(1650)\end{array}$ & 70 & $10-3$ & 80 & $11-7$ \\
\hline 1655 & 146 & 130 & $17-9$ & 36 & $4-11$ \\
\hline 1659 & & 90 & & 53 & \\
\hline 1662 & & 108 & & 60 & \\
\hline 1669 & 154 & 75 & 9.8 & 35 & $4-6$ \\
\hline 1677 & & 85 & & 24 & \\
\hline 1683 & $\begin{array}{c}184 \\
(1682)\end{array}$ & 120 & $13-1$ & 50 & $5-5$ \\
\hline
\end{tabular}

NOTA: la presión fiscal está medida en sueldos y dineros.

Fuente: AMP: Llibres de Claveria, 52/1 a 52/6. AMP: Llibres de Conselis, 49/1 a 49/3. Elaboración propia.

En el año 1634, junto a la tienda, taberna y panadería, el clavario de Petrer registra en su libro de cuentas gastos por el pago al colector del señorío de los molinos, los hornos de cocer pan, el herbaje y el bovalar. En este año 1634 el clavario ha trasladado al colector feudal 24 libras en concepto de administración municipal del herbaje, derecho reservativo que poseía el conde de Elda de las hierbas de huertas, olivares y viñas que riegan de la balsa de Petrer. Por el capítulo 
$10^{\circ}$ de la concordia de 1640 , dada entre la villa y su señor feudal, el conde cede la explotación del herbaje a la comunidad sin percepción económica alguna ${ }^{9}$ El bovalar, territorio inculto del interior montañoso del término, es utilizado por los vecinos de Petrer para el pastoreo de su ganado. Pero durante el s. XVII va generalizándose el arrendamiento de parte de este espacio a ganados transhumantes o al arrendador de la carne. Anualmente son arrendados conjuntamente el herbaje y la redonda (coto de pasto en el bovalar) a diferentes particulares, siendo el período de pasturaje otoño e invierno para las hierbas de los campos cultivados. Aunque los jurados gestionan el herbaje y el bovalar como propios de la villa, estos continúan siendo regalías señoriales pues, como dice el clavario en 1620 , únicamente están "prestats a la vila"10. Tras la concordia de 1640 la hacienda local obtiene con ello algunos ingresos que no son contrarrestados por abonos al conde de Elda como ocurre con la tienda, la taberna y la panadería.

En general, las rentas ingresadas por el clavario de Petrer por regalías y monopolios suponen alrededor del $25 \%$ de todos los ingresos locales, disminuyendo paulatinamente hacia el último tercio del s. XVII ${ }^{1 \mathrm{i}}$. La capacidad de incrementar los recursos financieros a partir de los propios y regalías es limitada. El bovalar y el herbaje mantendrán durante la segunda mitad del siglo su precio de arrendamiento. La Asegurada de la Harina, creada tras la concordia de 1640 con la pretensión de garantizar el abastecimiento local, aportará unos ingresos mínimos a la clavería de Petrer. Los hornos y los molinos, causa de pleitos entre la villa y el conde, únicamente serán administrados por los oficiales locales entre 1632 y 1640 . La taberna y la panadería pierden capacidad financiera. Las aguas, casas y tierras propiedad de la villa son prácticamente nulas. La tienda será la única regalía que aumentará durante esta centuria los ingresos por su explotación.

La elaboración de la Tabla $\mathrm{V}$ a partir de los precios del arrendamiento de las regalías permite observar cuáles serían los ingresos teóricos de la hacienda local a partir de estos monopolios, observándose que los ingresos teóricos totales se mantienen a lo largo del s. XVII. 
TABLA V.

Rentas teóricas de la hacienda de Petrer por regalías y propios.

\begin{tabular}{|l|l|l|l|l|l|}
\hline Año & Herbaje y Bovalar & $\begin{array}{l}\text { Asegurada de } \\
\text { Harina }\end{array}$ & $\begin{array}{l}\text { Taberna y } \\
\text { Panaderia }\end{array}$ & Tienda & TOTAL \\
\hline 1620 & 70 & & 59 & 54 & 183 \\
\hline 1634 & 25 & & 50 & 50 & 125 \\
\hline 1648 & 50 & 9 & 58 & 60 & 177 \\
\hline 1659 & 34 & 15 & 53 & 90 & 192 \\
\hline 1669 & 31 & 15 & 35 & 75 & 156 \\
\hline 1683 & 46 & 15 & 50 & 120 & 231 \\
\hline 1696 & 50 & 13 & 15 & 100 & 178 \\
\hline
\end{tabular}

Fuente: AMP: Llibres de Clavería, 52/1 a 52/6. AMP: Llibres de Consells, 49/1 a 49/3. Elaboraciôn propia.

\section{Impuestos indirectos: sisas y treta}

Los oficiales de la villa tienen capacidad para imponer arbitrios indirectos. Estos gravámenes recaen sobre las transacciones comerciales al por menor; es decir, la fiscalidad recae de este modo sobre el consumo. La hacienda municipal de Petrer registra dos figuras fiscales de imposición indirecta: las sisas sobre el consumo de la carne en la venta menuda de la carnicería y la treta, impuesto que recae en las mercadurías y productos que entran y salen del término de la villa. En general, la percepción tributaria local por estas imposiciones indirectas pierde importancia respecto a otras formas de contribución: en la primera mitad del s. XVII las sisas y la treta aportan a las arcas muncipales de Petrer una media anual del $25 \%$ de las rentas totales, y en 1696 ha descendido al $14 \%$. Así, la presión fiscal media por vecino a partir de estas imposiciones indirectas parece que disminuye, pues el precio del arrendamiento de estos arbitrios se mantiene durante toda la centuria y la población de Petrer, por contra, aumenta considerablemente. 
TABLA VI.

Presión fiscal por vecino de Petrer por imposición indirecta.

\begin{tabular}{||l|l|l|l|l||}
\hline \hline Año & Vecinos & Sisa (libras) & Treta (libras) & Sueldos/Vecino \\
\hline 1620 & $141(1624)$ & 100 & 51 & $21-5$ \\
\hline 1634 & $133(1636)$ & 75 & 40 & $17-4$ \\
\hline 1654 & $146(1655)$ & 100 & 52 & $20-8$ \\
\hline 1669 & 154 & 87 & 55 & $18-5$ \\
\hline 1683 & $184(1682)$ & 88 & 44 & $14-5$ \\
\hline 1690 & 195 & 91 & 35 & $12-10$ \\
\hline 1696 & 216 & 103 & 55 & $14-7$ \\
\hline \hline
\end{tabular}

NOTA: La presión fiscal está medida en sueldos y dineros.

Fuente: AMP: Llibres de Clavería, 52/1 a 52/6. AMP: Llibres de Consells, 49/1 a 49/3. Elaboración propia.

\section{A. Las sisas sobre el consumo de la carne}

La creación de sisas sobre los productos alimenticios en Petrer recae en el s. XV en el señor feudal. A partir de 1456, por licencia real, el entonces señor de la villa, Joan Roiç de Corella, conde de Cocentaina, impondrá sisas sobre el pan, vino, carne, pescado y otros alimentos en las villas de su dominio, entre las cuales está Petrer. Los ingresos que obtenga de esta detracción fiscal van destinados al amurallamiento del lugar ${ }^{12}$. Tras la expulsión morisca de 1609, el nuevo municipio cristiano gozará de la facultad de imponer sisas, pero únicamente lo hará sobre las carnes. El conde de Elda cede esta fuente fiscal a la villa, pero en ciertas coyunturas específicas hará uso de él. Así, el 24 de marzo de 1641 ordena epistolarmente a los oficiales que incrementen la sisa de la carne en 4 dineros por libra de peso, destinada la cantidad recaudada a Don Cristòfol Casanova ${ }^{13}$. 
TABLA VII

Sisas sobre el consumo de la carne en Petrer

(dineros/libra de peso).

\begin{tabular}{||l|l|l|l|l|l||}
\hline Año & Dineros/Libra & Año & Dineros/Libra & Año & Dineros/Libra \\
\hline 1617 & 4 & 1635 & 7 & 1652 & 6 \\
\hline 1621 & 6 & 1641 & 4 & 1654 & 6 \\
\hline 1629 & 6 & 1648 & 6 & 1660 & 4 \\
\hline 1633 & 36 & 1651 & 4 & 1696 & 5 \\
\hline
\end{tabular}

Fuente: AMP: Llibres de Clavería, 52/1 a 52/6. AMP: Llibres de Consells, 49/1 a $49 / 3$. Elaboraciôn propia.

La sisa, como se observa en la Tabla VII, varía entre unos límites estrechos en la fase estudiada. El gravamen fiscal sobre la carne expedida en la carnicería de Petrer que predomina durante el s. XVII es de 4 dineros por libra de peso. Esta tasa variará en momentos coyunturales, para atender algún gasto específico y eventual: arreglo de un establecimiento comunitario, pago de intereses crediticios, cubrimiento de las contribuciones y requisitorias del Real Patrimonio o de la Generalitat, atención de las solicitudes monetarias realizadas a la villa por el conde de Elda. Por ejemplo, el Consell Particular celebrado el 18 de febrero de 1652 establece una sisa general de 6 dineros por libra, al estar la villa de Petrer

"ab molt gasto per los salaris que dona y mes per los intereses que
correspon de cambis y aiximateix ab poch recibo per lo poch que
la sisa y la treta y altres regalies monten que vegen sus merces si
es podia augmentar lo arrendament de treta y sisa en cada lliura
de cada cosa"14.

Comparando la sisa sobre la carne que abunda en Petrer con otras localidades, se observa que en los grandes núcleos urbanos hay una tendencia durante el s.XVII a incrementar la imposición fiscal indirecta sobre el consumo. En Orihuela se llega a una sisa de 12 dineros por libra de carne comprada, en la Gandía ducal en los capítulos de arrendamiento de las sisas para el año 1688 se fija la de moltó en 15 dineros y en 9 dineros la de ovella y cabró y en la ciudad de València la carne de moltó contribuye con 24 dineros por libra pesada ${ }^{15}$. 
La imposición fiscal sobre la carne, si relacionamos los datos de la sisa con los precios de la carne vendida en la carnicería de Petrer, representa entre el 8 y el $19 \%$ del precio de venta según el año y el tipo de carne. En la ciudad de Orihuela, a mediados del s. XVII, la carne de macho es expedida al público por 44 dineros la libra de peso, de los cuales el $27 \%$ correspondía a sisas municipales; en Pètrer, en las mismas fechas, esta carne de macho cabrío tiene un precio en la carnicería entre 38 y 40 dineros, correspondiendo a la contribución indirecta por su consumo el $10-16 \%$ de dicho precio de venta ${ }^{16}$.

TABLA VIII.

Imposición fiscal indirecta sobre la carne expedida en la carnicería de Petrer (en dineros).

\begin{tabular}{||l|l|l|l||}
\hline Año & $\begin{array}{l}\text { MACHO CABRÍO } \\
\text { Precio/Sisa en \% }\end{array}$ & $\begin{array}{l}\text { CARNERO } \\
\text { Precio/Sisa en \% }\end{array}$ & $\begin{array}{l}\text { OVEJA } \\
\text { Precio/Sisa en \% }\end{array}$ \\
\hline 1628 & $36-6-17$ & $38-6-16$ & $34-6-18$ \\
\hline 1635 & $44-7-16$ & $36-7-19$ & $36-7-19$ \\
\hline 1651 & $40-4-10$ & $52-4-8$ & $40-4-10$ \\
\hline 1654 & $38-6-16$ & $50-6-12$ & \\
\hline 1701 & $24-4-17$ & $36-4-17$ & \\
\hline
\end{tabular}

Fuente: AMP: Llibres de Consells, 49/1 a 49/3. Elaboración propia.

La recaudación de la sisa de la carne era arrendada por la villa. El arrendatario del abasto de la carne y de la carnicería también solía arrendar el cobro de la sisa de la carne. El arrendamiento se realizaba en subasta pública por el ministro en la lonja de la villa, el cual ha "tancat y remat lo avituallament de les carns de la present Vila ab veu publica en presencia de Pere Maestre regent de Justicia, Vicent Alcaras, Baltazar Peres y Pere Paya de Gregori Jurats en la llonja de la dita vila conforme capitols" ${ }^{17}$. El arrendamiento es casi siempre por un período anual. En ocasiones el arriendo puede ser de dos o cuatro años. Cuando hay problemas para arrendar la percepción de la sisa, ésta es administrada directamente por los oficiales de la villa por un período de tiempo corto, de varias semanas, coincidiendo algunas veces con las celebraciones pascuales. Para el control del abasto de la carne y de las sisas el arrendador debía llevar el llibre de la carn, en el cual anota la carne expendida, las cantidades cobradas, la correspondiente sisa y el comprador ${ }^{18}$. 
El mantenimiento a lo largo de la mayoría de los años del s. XVII de una sisa sobre la carne de 4 a 6 dineros y el aumento demográfico dado en la nueva comunidad cristiana repobladora ${ }^{19}$, teóricamente darían como resultado un incremento de los ingresos hacendísticos por esta figura fiscal. Esto debería plasmarse en el arrendamiento anual de la recaudación de la sisa de la carne que, contrariamente, mantiene a lo largo de la centuria precios del arriendo equivalentes tal como se observa en la Tabla VI.

Motivos para que el precio del arrendamiento de la sisa no puje al alza pueden ser la tendencia al autoabastecimiento familiar, la más que segura disminución en el consumo per cápita de carne de ganado menor y, mínimamente, la exención fiscal de algunos miembros de la comunidad. La estructura de la propiedad agraria irrigada delata la tendencia al aumento de las familias campesinas con posesiones pequeñas, inferiores a una hectárea: en el año 1636 son casi la mitad de los enfiteutas y en 1682 ya representan el $77 \%$. Con menos de una hectárea de regadío en la huerta petrerina una familia estará en el umbral de subsistencia, por lo que estos vecinos deberán completar los ingresos familiares con otras actividades (explotación agraria de las improductivas tierras montañosas, recolección en los montes, actividades artesanales y comerciales complementarias ... $)^{20}$. El aumento de estos vecinos se observa en la consideración de pobres: en el año 1667 una relación fiscal de los vecinos de Petrer inscribe a 132 pagadores, 2 eclesiásticos y 17 pobres. En los libros de cuenta del clavario de Petrer se habla de los pobres de la parroquia, de los pobres de la vila y de los pobres vergonyants, entre los cuales la institución municipal reparte pequeñas entregas benéficas en dinero y en alimentos. La entrega de alimentos se realiza en fechas de celebraciones religiosas: en 1648 se registran en los Libros de Clavería gastos por carne dada a los pobres en carnestoltes; en 1669 a los pobres de la vila se les reparte "pa, vi y dines per a festes de Nadal"; en 1676 se les reparte carne en pascua de resurrección ... ${ }^{21}$.

En los años centrales del s. XVII disminuye el consumo de la carne expedida en la carnicería de la comunidad rural. En el año 1648 los 582 habitantes de Petrer consumen 3.960 libras de peso de oveja, carnero y macho cabrío y en el año 1654 los 620 habitantes sólo consumen 3.227 libras de peso. Esto es, el consumo per cápita de carne pasa de $6^{\prime} 8$ libras por habitante a $5^{\prime} 2$ libras $^{22}$.

La iglesia de Petrer está atendida por tres eclesiâsticos, exentos del pago de la sisa general sobre la carne. El clero pagará la sisa sólo por necesidad financiera para la atención de algún gasto eventual. Esto ocurre en 1704, cuando el consejo particular acuerda, y el clero accede, en cobrar la sisa de la carne al cura párroco y a los vicarios para sufragar parte del gasto de una campana ${ }^{23}$. Junto al clero, exento de pagar la sisa de la carne, se sumará en el último tercio del s. XVII Don Joan Avellán i Gosalbes que, como declara años más tarde su hijo, es "hijodalgo de sangre desde su Padre y Abuelo y demás descendientes por línea recta de varon de tiempo inmemorial a esta parte"24. 
El contrato municipal con el maestro, el médico, el veterinario o el barbero incluye, en algunas ocasiones, la exención de pagar impuestos, que cualquiera de estos profesionales quede "franch de tota imposició com es tacha, sisa i soldats". Esta franquicia fiscal es causa de desavenencias entre los oficiales y los profesionales contratados. En octubre de 1704 el doctor Lluis Maestre, arguyendo su condición privilegiada, no paga el reparto de los soldats dels Estaments hecho por los jurados entre todo el vecindario. Ante la disputa entre oficiales y médico interviene el conde de Elda, recriminando a los oficiales por haber cobrado tachas y sisas al médico, pues está exento, a la vez que eclesiásticos y militares, y "como graduado de Doctor de esta Universidad (de València) gozava de privilegio militar". Finalmente, el conde obliga a que le sean devueltas las 30 libras que los oficiales de la villa le han sustraído del salario para cobrar las sisas y tachas municipales ${ }^{25}$.

\section{B. La treta, arbitrio indirecto sobre mercadurías}

El comercio local estaba gravado con cuotas fijas en Petrer. La treta es la imposición indirecta que recae sobre los productos que entran o salen de la villa. Los oficiales de la villa tienen capacidad para establecer y variar la cantidad de esta sisa general de mercadurías. Según la coyuntura financiera de la hacienda local y el estado y necesidades de productos básicos por la comunidad rural, la tasa fiscal impuesta por los oficiales municipales variará a lo largo del s. XVII. Así, en 1652, para el imperioso cubrimiento de gastos hacendísticos, el Consell Particular acuerda doblar la treta del trigo y de otras mercancías, estableciendo la tasa en 6 dineros por libra de moneda $\left(2^{\prime} 5 \%\right)^{26}$. En primavera de 1635 el conde de Elda ha visitado la villa de Petrer, organizando en la comunidad celebraciones y entregando regalos a la familia condal. Estos elevados dispendios pretenden ser cubiertos con el aumento de la treta, pero la imposibilidad de arrendar a algún particular la recaudación de este impuesto, hace que el consejo particular revoque el incremento de la tasa y esta vuelve a su nivel normal, esto es, 3 dineros por libra de moneda $\left(1^{\prime} 25 \%\right)^{27}$.

Esta sisa general de mercadurías gravaba ordinariamente la salida de productos de la villa. Mediante la treta se trata de garantizar el abastecimiento interno con la producción local, atrayendo a los comerciantes foráneos con la inexistencia de obstáculos fiscales en momentos de escasa producción interna y limitando la entrada de mercancías con una tasa contributiva cuando la villa es excedentaria. El primer artículo de los capítulos de arrendamiento de la treta de 1621 lo confirma:

"Primo, per cascun cafis forment dos sous y per cafis sivada, panis, senteno hun sou per cafis y qualsevol altre genero de mercaderia tres dines per lliura que eixira de la present vila y el vehi de la terra oforaster que portara mercaderia a dita vila vena francament y lo que no vendra o traga franch" 28 . 
Esta es la norma general en el control local del comercio, pero hay excepciones y no sólo el campesino o traginero que "traure qualsevol mercaduria a vendre fora la present vila aja de pagar"29. En el mismo contrato de arrendamiento de la treta del año 1621 , el capítulo $4^{\circ}$ establece que cualquier mercancía que entre en Petrer para ser vendida y "sia consemblants als fruits $y$ rentes que scullen en la present vila aga de deure treta". En 1652 la medida tiene unos claros tintes recaudatorios, pues el tipo fiscal es el doble al normal (6 dineros por libra de moneda) y afecta a todas las mercaderías que entren o salgan de la villa ${ }^{30}$.

Junto a los productos que figuran en la Tabla IX, cabe destacar la restricción del comercio de animales de transporte y labranza. En 1617 el vecino que permutare una cavalgadura fuera de la villa, tendrá la obligación de pagar en concepto de treta "les millores que traura de la vila" y en 1621 se establece que el vecino "que traura cavalgadura de los termes dega tres dines per lliura de lo que tornara" ${ }^{31}$. Las mulas, los machos de tregí y los machos de llauro escasean en la comunidad rural, por lo que se crean trabas fiscales a su comercio foráneo.

TABLA IX.

Treta sobre las mercaderías que salen de la villa de Petrer.

\begin{tabular}{||l|l|l|}
\hline & 1621 & 1641 \\
\hline TRIGO & 24 dineros/cahiz & 48 dineros/cahiz* \\
\hline CEBADA & 12 dineros/cahíz & \\
\hline CENTENO & 12 dineros/cahíz & \\
\hline PANIZO & 12 dineros/cahiz & 24 dineros cahíz \\
\hline PASAS & & 12 dineros/quintal* \\
\hline RESTO MERCADERIAS & 3 dineros/libra & 3 dineros/libra \\
\hline & Valor & Valor \\
\hline
\end{tabular}

* Pagado a partes iguales por vendedor y comprador.

Fuente: AMP: Llibres de Consell, 49/2. Capítulos de arrendamiento del 22 de marzo de 1621 y del 24 de marzo de 1641. Elaboración propia. 
La percepción del dret de la treta es arrendada anualmente por los representantes municipales en pública subasta, siendo el período de gestión desde el inicio de la primavera hasta finales del invierno siguiente o, más exactamente, es el dia de la encarnacio de la mare de deu el que marca el año de arrendamiento ${ }^{32}$. Para que el arrendatario controle lo más fielmente posible el comercio de productos, los agricultores y carreteros que entren o saquen mercancías de la localidad tienen la obligación de declararlo ante el arrendatario de la treta en un período determinado de tiempo (entre 24 horas y 8 días), bajo pena de 60 reales si incumplen la reglamentación. Observando la Tabla $\mathrm{X}$ donde el precio del arrendamiento anual de la recaudación del derecho de treta no sigue la línea ascendente de la demografía local, es de suponer que o bien la evasión fiscal del aumentado vecindario es importante o bien hubo un grado de autoabastecimiento local que limitaba la recaudación fiscal sobre el comercio.

TABLA X.

Precios del arrendamiento anual de la treta de Petrer.

\begin{tabular}{||l|l|l|l|l|l||}
\hline Año & LIBRAS & VECINOS & Año & LIBRAS & VECINOS \\
\hline 1620 & 51 & & 1662 & 61 & \\
\hline 1627 & 55 & & 1669 & 55 & 154 \\
\hline 1634 & 40 & $133(1636)$ & 1670 & 43 & \\
\hline 1641 & 50 & & 1676 & 41 & \\
\hline 1648 & 60 & & 1677 & 38 & $188(1678)$ \\
\hline 1651 & 31 & $137(1650)$ & 1683 & 44 & $184(1682)$ \\
\hline 1654 & 52 & & 1690 & 35 & 195 \\
\hline 1655 & 52 & 146 & 1696 & 55 & 216 \\
\hline \hline
\end{tabular}

Fuente: AMP: Llibres de Clavería, 52/1 a 52/6. AMP: Llibres de Consells, 49/1 a 49/3. Elaboración propia.

\section{Impuestos directos: tachas y repartos}

Un capítulo importante en la hacienda municipal es la fiscalidad directa. Se consideran impuestos directos aquellos que se establecen sobre la propiedad o renta de individuos o instituciones. Estos cargos directos, según el método de imposición aplicado, pueden ser de cuota fija por vecino o habitante -método por el que la 
equidad es un factor secundario-, método proporcional a la capacidad económica de cada contribuyente o método progresivo en aras de una mayor contribución fiscal de los mayores patrimonios.

Las contribuciones directas son parte destacable de las finanzas locales, por cuanto son obligaciones con que se arbitran fondos para gastos públicos del municipio. Las tasas fiscales aplicadas dependerán, pues, de las necesidades del gasto municipal y éste, a su vez, tanto de la atención de la comunidad como de los niveles de presión de poderes extramunicipales para obtener parte del excedente agrario a través de la fiscalidad. Es decir, las prestaciones señoriales, variables en el tiempo por el devenir de las relaciones sociales entre el señor feudal y los vecinos de la villa, las exigencias fiscales de la Diputaçió de la Generalitat y las cada vez más numerosas detracciones del estado absolutista, influyen en la composición de la hacienda municipal y en la presión fiscal directa sobre la comunidad rural.

Es evidente el incremento de las percepciones tributarias del municipio por arbitrios directos: repasando la Tabla I, se observa que la clavería de Petrer duplica los ingresos reales en concepto de imposición directa. Es el salto más sobresaliente en la participación porcentual, pasando las percepciones tributarias directas de ser el $27 \%$ del total de los ingresos reales de la tesorería local en el año 1620 a suponer el $45 \%$ en $1696^{33}$.

\section{A. Repartos municipales}

Entendemos por tachas municipales los arbitrios directos impuestos por los oficiales locales sobre el vecindario para obtener ingresos destinados al gasto local interior. Son repartos hechos para pagar salarios y créditos, para abonar los censos de la lonja o "per a subvenir els gastos que la vila se obliga de correspondre cascuny any" ${ }^{34}$. Estos repartos dependen en buena medida del nivel de gastos ordinarios y extraordinarios habidos durante el año, así como también están en relación con el nivel de ingresos de otras rentas municipales que pueden repercutir sus menores entradas en un aumento de los repartos. En julio de 1703 el consejo particular acuerda recaudar 80 libras como tacha entre los contribuyentes de Petrer "...per quant les regalies estaven arrendades a magiors cantitats de lo que estan enguany" 35 .

Este primer tipo de arbitrio directo recibe el nombre genérico de tacha, cuyos ingresos están consignados a gastos diversos de la administración. El volumen de la imposición, variable anualmente, que grava a toda la población, lo establece el consejo particular a propuesta del jurat en cap que solicita a los consejeros que fasen una tacha para subvenir determinados gastos.

El poder fiscal práctico recae sobre los órganos administrativos locales de la villa, aunque en las primeras décadas de la repoblación la tensión entre el conde 
de Elda y la comunidad rural también se refleja en el poder fiscal. En el primer tercio del s. XVII, entre los diversos pleitos iniciados en la Real Audiencia valenciana entre la villa y su señor feudal, hay un proceso "sobre que la dita vila pretengue que lo dit Comte no podia prohibirlos que no possasen impossicions y taches sens sa llicensia" ${ }^{36}$. La concordia de 1640 , que dio salida a los conflictos entre los oficiales y el conde, no hace referencia sobre quien posee la potestad de imponer estas tasas fiscales. Los Llibres de Consells, reflejo de la actividad del poder local, recogen continuos acuerdos del consejo particular sobre el reparto de tachas entre los vecinos de Petrer, aunque la doctrina y la jurisprudencia de la Real Audiencia valenciana atribuyen, generalmente, a los señores baronales la facultad de autorizar impuestos municipales.

El método de imposición aplicado varía temporalmente. El 12 de febrero de 1617 el consejo particular acuerda tachar a los contribuyentes con una cuota fija: "fonch resolt per la major part del consell ques fasa tacha a tres reals per cassa"37. En otras coyunturas el acuerdo es una contribución de los vecinos proporcional al patrimonio y renta. Así lo especifican los consejeros en febrero de 1704 cuando acuerdan "fer repartiment per la vila present a cascu conforme tendra de asienda"38. Desde mediados del s. XVII son elaborados los Llibres de repartiment y tacha en los cuales aparecen listas nominales de los vecinos de Petrer entre los que se distribuye proporcionalmente a la riqueza económica de cada uno (per escales) la tacha aprobada por el consejo particular. Así, por ejemplo, en 1669 las cargas fiscales de los 154 vecinos registrados varían entre $1^{\prime} 5$ y 30 reales $^{39}$. En la distribución de la derrama se tienen en cuenta los casos de "els pobres (que) estan $a b$ molta necessitat" ${ }^{40}$ y la colecta no afectará a mosén Onofre Esteve, clérigo de la localidad.

Aparte de esta tacha genérica y anual, también se incluyen en este apartado de repartos municipales aquellos realizados en momentos concretos por algún gasto local de relevancia. El recurso al arbitrio directo extraordinario es abundante en Petrer: en 1617 se realiza una tacha de cuota fija para financiar los gastos de los procesos judiciales que la villa tiene en curso; en 1630 se hace un repartimiento de 137 libras por la construcción del azud; en 1640 hay una derrama para cubrir deudas de la villa en Monforte - 100 libras- y en Monòver -60 libras-; en 1642 por las exigencias estatales del pago de cinco soldados para Cataluña acuerda el consejo particular cubrir el gasto con un reparto entre el vecindario; en 1645 se hacen dos derramas directas ocasionales, una de 50 libras para cubrir la leva militar de los Estaments y otra de 40 libras destinadas a la tribuna de la iglesia parroquial ... ${ }^{4 \mathrm{i}}$.

Un reparto que permanecerá entre 1679 y 1737 es el realizado entre el vecindario de Petrer para pagar las pensiones de los censales tomados por la villa para la construcción del pantano en el estrecho de Catí. Este tercer arbitrio directo municipal es pagado por los agricultores de tierras huerta, olivar y viña que utilizan las aguas de riego de la balsa. Entre los regantes es repartida la tacha del pantano 
proporcionalmente a las tahúllas irrigadas y a "les tandes de la aygua a quinze dines cada tanda"42.

Un arbitrio específico, y como tal hay que destacarlo, es el repartiment del doctor. El salario del médico contratado para atender a los habitantes de Petrer es el más elevado de los respondidos por el clavario, alcanzando en muchos años $1 / 3$ del gasto destinado a retribuciones de oficiales y empleados, absorviendo en torno al $10 \%$ de todo el gasto general de la villa en ciertas coyunturas. Las más de 100 libras del salario del médico es motivo para que los jurados elaboren un libro de repartos para recaudar mediante imposición directa la cantidad que ha de ser abonada anualmente al médico. Desde el primer año que es contratado un médico, en 1634, y sobre todo desde 1662 que ya aparece regularmente la tacha del doctor, es evidente que este servicio médico repercute sobremanera en la fiscalidad local aumentando los arbitrios directos. El método de imposición tiene en cuenta el patrimonio familiar, pues la contribución de los 153 vecinos de la nómina registrada en 1669 variará entre un mínimo de dos reales y un máximo de doce reales.

\section{B. Reparto del agua de Elda}

Entre las rentas feudales obtenidas en la baronía de Petrer por el conde de Elda figuran 75 libras por el concierto del agua de Elda. El convenio supone la administración municipal de las aguas que desde el río Vinalopó, en el término de Elda, "reguen les viñes de baix de la present vila"43. El conde de Elda posee el derecho reservativo sobre las aguas y por esta regalía la villa de Petrer abonará anualmente al colector condal 75 libras. La prestación señorial repercute en la hacienda local que recauda la cantidad a pagar al conde de Elda mediante arbitrio directo entre la población. Las derramas por el agua de la villa de Elda se realizarán en torno al día de todos los santos, bien haciendo el reparto los oficiales o arrendando esta recaudación en subasta pública. En contraste con las regalías de establecimientos de producción y comercialización que son arrendadas a particulares $\mathrm{y}$, en última instancia, repercutirán fiscalmente sobre todos los habitantes de modo indirecto al incidir en los precios de los productos y servicios el precio del arrendamiento, esta regalía de las aguas de Elda es recaudada mediante impuesto directo únicamente sobre los regantes.

La imposición fiscal sigue un método proporcional. Para ello se elaboran listas nominales, como es muestra la "Seda del aigua de Elda de este any 1659 la qual ha de cobrar Francesc Montesinos de Christoval arrendador de aquella que se li trança en una lliura catorse sous" ${ }^{44}$. En ella aparecen 97 nombres de poseedores de tierras irrigadas de las viñas de abajo que pagarán entre 7 sueldos 6 dineros y 60 sueldos, lo cual significa que el reparto es proporcional al patrimonio de regadío de cada familia campesina. 


\section{Impuestos directos por exacciones estatales}

En este apartado describiremos la recaudación de tributos realizada por los oficiales locales mediante el reparto proporcional o fijo entre el vecindario para atender las exigencias fiscales estatales. La hacienda municipal es involucrada por las instituciones estatales para recaudar contribuciones que son transferidas desde la villa a los centros políticos de Orihuela, Alacant, València o Madrid.

\section{1. Derechos de la sal y del "general del tall".}

Estos derechos son impuestos recaudados por los administradores del Real patrimonio y por los Diputats de la Generalitat respectivamente desde la Baja Edad Media. Utilizan las infraestructuras de las instituciones municipales para la colecta en pueblos y villas. Por tanto, aparecen computados en el cargo y descargo de los libros de clavería municipales.

El dret de la sal era un gravamen consistente en pagar una cuota fija por cada casa habitada. El clavario de Petrer ingresa en las arcas municipales una cantidad que varía poco a lo largo del período estudiado en este trabajo, debido más al estanco de esta cantidad que al número de casas, el cual aumentará paulatinamente. Para realizar la derrama y la percepción tributaria son elaborados unos cuadernos nominales con los nombres de los vecinos de Petrer que han de contribuir al pago de este impuesto directo. La tasa es fija, estableciéndose en 1687 , por ejemplo, dos cuotas entre el vecindario: una de 5 sueldos y otra de 2 sueldos 6 dineros.

El cobro de este derecho es arrendado en subasta pública en la lonja. El arrendatario local se compromete a cobrar los gravámenes que figuran en el "Llibre y repartiment del real de la sal y la sal de Gavelles y Gavellot", pagando la cuota asignada a la villa en la ciudad de Valencia y a presentar cuentas y recibos a los oficiales de la villa ${ }^{45}$.

Junto al cobro del derecho de la sal es percibido también el derecho del general del tall. Este impuesto recae sobre el vecindario por el corte de la ropa, esto es, por la confección y tráfico de telas. Para el cobro de este derecho, administrado por la Diputaçió de la Generalitat, se establece una cuantía fija para toda la población de Petrer que en la segunda mitad del s. XVII se estabilizará en 32 libras. Los oficiales de la villa reparten esta consignación entre los vecinos mediante un arbitrio directo. Las cuotas variarán de 1 sueldo 6 dineros a 6 sueldos. 


\section{2. Cargas militares}

Una serie de impuestos directos son recaudados por los oficiales de Petrer debido a las cargas militares que impone el estado. El conflicto sucesorio por la corona española marca una divisoria entre las cargas militares habidas en el s. XVII y las dadas en el s. XVIII.

Durante el s. XVII, en unas ocasiones directamente envía la villa el número de soldados solicitados, como lo hace en mayo de 1650 al convocar Consell General para reclutar mediante redolins, "tres piquers, tres mosqueters y sinch arcabucers" que deberán ir provistos de armas. En otras ocasiones se realizan repartos entre las casas del lugar para recaudar dinero y pagar el número de soldados asignados, o se divide la población en quadrelles respondiendo cada una de cierta cantidad monetaria. A tal fin son elaborados memoriales nominales, los "Llibres dels soldas dels estaments", donde figuran los vecinos de la villa y la cantidad gravada. Es decir, en este caso del impuesto casi permanente y obligatorio que llega a ser durante la segunda mitad del s. XVII el subsidio de los "soldats dels estaments del Terç del servici que esta a sa Magestat", se sigue el mismo proceso ya descrito en otras imposiciones directas de asignación global a la villa: organización de ésta para el reparto entre los vecinos, elaboración de listas nominales para la tasación y el control recaudatorio y el traslado de la cuantía a València. El método de imposición directa proporcional a la riqueza queda al arbitrio de los oficiales de la villa, como es ejemplo el consejo particular de 1653 que aprobó que "fasa derrama i repartiment entre los vehins de la present villa repartint a cada hu allo que en ses consiensies conexeran los señors Justicia i Jurats poden pagar cada un vehi ${ }^{+46}$.

Otra fórmula de imposición directa es la división de la villa en varios distritos, quadrelles. En junio de 1656 la ciudad de Alacant demanda soldados para su defensa, dividiendo los oficiales la villa de Petrer en "sis quadrelles" para hacer frente a esta solicitud y obligándose cada distrito vecinal a enviar un hombre semanalmente, pagándose los gastos a partir de una cuota fija por vecino ${ }^{47}$.

Las protestas por estas exigencias militares se manifiestan en las quejas de los magistrados locales por hallarse las arcas municipales exhaustas y por estar la villa pobre, cargada e imposibilitada. Las exigencias de soldados, dinero, armas, pólvora y otros utensilios destinados al ejército provoca estas quejas entre los oficiales de la villa y se expresarán en las rebajas continuas que de las prestaciones exigidas solicitan y llevan a cabo los mismos oficiales. En agosto de 1653 el consejo particular acuerda ayudar con 600 reales castellanos, no con mil como se habia establecido inicialmente, a la demanda virreinal para el ejército de Cataluña a pesar de "la gran pobresa de la present vila $i$ vehins de aquella i la poca collita que en lo present any y hagut $i$ que esta empeñada en molts quantitats"48. 


\section{Recurso al crédito}

Cuando las necesidades financieras de la hacienda municipal petrerina desbordan los mecanismos de ingresos descritos hasta aquí, aún queda el recurso al crédito para cubrir diferentes gastos locales. Es decir, el endeudamiento de la clavería depende en buena medida del nivel de gastos ordinarios y extraordinarios habidos durante el año, así como también está en relación con el nivel de ingresos de las regalías y de los tipos fiscales aplicados. En general, el recurso al crédito supone porcentajes medios inferiores al $20 \%$ de los ingresos totales de cada año, exceptuando los elevados empréstitos extraordinarios.

Establecer el volumen total de ios préstamos tomados por la villa durante el s. XVII resulta difícil, por cuanto las fuentes documentales conservadas no permiten un estudio exhaustivo y pormenorizado. La Tabla XI recoge aquellos préstamos dados a la villa en diferentes momentos que han podido ser identificados. En ella se distinguen dos tipos de créditos.

Uno es el préstamo a canvi, el cual generalmente no posee un tiempo límite para amortizar el capital ni una garantía hipotecaria. Supone un gasto elevado por los altos intereses abonados (superiores al $10 \%$ ). La mayoría de estos empréstitos son cantidades no superiores a 200 libras, cedidas por vecinos de Petrer o de localidades cercanas (Elda, Castalla, Onil, Monòver, Monforte) y destinadas al abastecimiento cerealícola de la comunidad, a la reparación de instalaciones públicas, al pago de alguna retribución salarial o de algún crédito vencido, al pago de las regalías y al abono de las cantidades exigidas por las instancias monárquicas para sus campañas militares.

Otro tipo de empréstitos es el censal, variedad crediticia que es definida como "derecho, garantizado con hipoteca, de percibir una pensión dineraria actual. adquirido por compra con pacto de retro" ${ }^{\prime 4}$. El interés desde 1614 es del $5 \%$, inferior al rédito de los canvis, "obligantse los bens de dita vila"sc. Los censales de Petrer van dirigidos, aparte de ciertas cantidades pagadas al erario real o para el abastecimiento de la villa, a obras públicas de envergadura. Destaca la financiación del pantano en el estrecho de Catí, que supuso el cargamiento de tres censales: 1000,800 y 500 libras (el rédito anual de este último, 25 libras, las responderá el conde de Elda y el colector señorial las ingresará anualmente en la clavería municipal). En este caso de la deuda consolidada, los dueños de los capitales prestados son todos foráneos (Alacant, Onil, Elda...) y son eclesiásticos, militares, ciudadanos o generosos. 
TABLA XI

Muestra de créditos ingresados en la clavería de Petrer (1620-1707).

\begin{tabular}{|c|c|c|}
\hline Año & $\begin{array}{l}\text { A CANVI } \\
\text { LIBRAS PRESTAMISTA } \\
\text { DESTINO }\end{array}$ & $\begin{array}{l}\text { CENSAL } \\
\text { LIBRAS PRESTAMISTA } \\
\text { DESTINO }\end{array}$ \\
\hline 1620 & 143 & \\
\hline 1643 & 200 Soldados & \\
\hline 1648 & $\begin{array}{l}200 \text { leva Tortosa } \\
100 \text { leva Tortosa } \\
100 \text { a A. Rico } \\
50 \text { de Castalla (Trigo) } \\
20 \text { de Castalla (predicador) } \\
100 \text { Regalias }\end{array}$ & \\
\hline 1649 & $100-($ Sala Vila $)$ & \\
\hline 1654 & $\begin{array}{l}200^{*} \text { P. Marquino } \\
200^{*} \text { Joan Peres (Petrer) }\end{array}$ & \\
\hline 1676 & & $\begin{array}{l}1300^{*} \text { D. Picó, miles (Alicante) } \\
300^{*} \text { El mismo } \\
200^{*} \text { El mismo }\end{array}$ \\
\hline 1680 & & $\begin{array}{l}500 \mathrm{~T} . \text { Berenguer (Ciutatà) } \\
\text { Pantano } \\
1000 \mathrm{M} \text {. Joan (Onil) Pantano } \\
800 \text { Clero de Onil Pantano }\end{array}$ \\
\hline 1682 & $\begin{array}{l}50 \text { Barlonguera (Petrer). Réditos } \\
\text { de Censales. }\end{array}$ & \\
\hline 1690 & $250 *$ F. Joan (Ciutatà, Onil) & $\begin{array}{l}1300 * \text { F. Caniçia, noble } \\
\text { Alicante }\end{array}$ \\
\hline 1696 & 250 G. Rico. Onil & \\
\hline 1700 & 1000 - Trigo & \\
\hline 1707 & & $1000^{*} \mathrm{~T}$. Semper (Elda) \\
\hline
\end{tabular}

* La noticia documental corresponde a este año pero su cargamiento debe ser anterior.

Fuente: AMP: Llibres de Claveria, 52/1 a 52 /6. AMP: Llibres de Consells, 49/1 a 49/3. ARV: Escribanías de Cámara, Año 1720, exp. 26 y año 1735, exp. 49. ARV: Bailía, letra P-I, leg. 137. Elaboración propia. 
Durante la primera mitad del s. XVII predominan los préstamos a canvi. En el último tercio de la centuria la orientación crediticia de la villa de Petrer se dirige a los censales, por lo que la deuda consolidada aumentará. El cambio de dirección bien puede explicarlo el jurat en cap en octubre de 1656:

"... la present vila esta hui molt exausta i pobre de tal manera que esta hui responent cambi de mes de mil lliures de Lluch Berenguer de Castalla i a Isabel Joan Dura viuda de Pere Marquino i a Joan Peres major desta vila i que tan solament les fires de dits cambis no les pot pagar la present vila per la molta pobresa de aquella $i$ que cascun any importen les fires de dits cambis mes de cent sinquanta lliures $i$ que molta part de aquelles es poden redimir de manera que la pensio de les quantitats de dits cambis vinguen a ser meñs en gran suma, en esta manera que es mire i tratege si aura alguna persona que vulla donar dita quantitat que la vila te a cambi carregantsela a sensal i desta manera si es trobat qui donas dita quantitat a sensal nos respondria mes de sinquanta o sinquanta sinch lliures cascun any"51.

El recurso al crédito para equilibrar las finanzas locales repercute en un aumento del gasto. El pago de intereses y la amortización de la deuda van a ser partidas permanentes a las que tiene que responder la clavería municipal. El volumen teórico que debe responder la villa por los censales puede seguirse en la Tabla XII.

Las consecuencias de este endeudamiento municipal es doble. Una es el conflicto censalista, esporádico en el s. XVII y estructural con los cambios borbónicos $^{52}$. Y otra, la que aquí deseamos destacar, es la repercusión en la fiscalidad local ${ }^{53}$. Para cubrir parte de las obligaciones crediticias se incrementary tanto la sisa y la treta como los arbitiros directos. Las derramas para cubrir "les fires del cambi" y para amortizar los préstamos se suceden a lo largo de la centuria. El 15 de agosto de 1618 el consejo particular acuerda hacer una tacha para cubrir una deuda crediticia mediante un reparto entre el vecindario ${ }^{54}$. El caso más llamativo de fiscalidad directa con un origen crediticio son las 90 libras que anualmente deben pagar los enfiteutas de tierras de regadío para abonar las pensiones de 1.800 libras de censales destinadas a la construcción del pantano.

En la Tabla XII aparece una columna del gravamen medio por vecino que debe responder la villa por las pensiones de los censales cargados. Este pago, con repercusiones fiscales indudables, se triplica en un período de tres décadas. 


\section{TABLA XII}

Gasto teórico anual de la clavería de Petrer en pensiones de censales cargados a la villa.

\begin{tabular}{||l|l|l|l|l||}
\hline Año & $\begin{array}{l}\text { PRINCIPAL } \\
\text { (Libras) }\end{array}$ & $\begin{array}{l}\text { PENSIÓN } \\
\text { (Libras) }\end{array}$ & VECINOS & $\begin{array}{l}\text { SUELDOS } \\
\text { VECINO } \\
\text { (Pensín) }\end{array}$ \\
\hline 1676 & 1800 & 90 & 181 & 9.9 \\
\hline 1683 & 4100 & 205 & 206 & 19.9 \\
\hline 1690 & 5400 & $270^{* *}$ & 203 & 26.6 \\
\hline 1707 & $5900^{*}$ & 295 & $214(1709)$ & 27.5 \\
\hline 1716 & 6050 & 302 & $245(1715)$ & 24.7 \\
\hline
\end{tabular}

* Quitamiento en 1707 de un censal de 500 libras.

*:* Exención de 15 libras por el censal de F. Caniçia. Elaboración propia.

\section{Consideraciones finales}

Una recapitulación del sistema fiscal de la hacienda municipal de Petrer permite observar el elevado peso de los impuestos. La generación de recursos financieros por parte de la clavería local se orienta hacia los arbitrios directos (el $28 \%$ en 1620 y el $46 \%$ en 1696), dado que las rentas por bienes de propios están estancadas, al igual que los ingresos monetarios obtenidos por la explotación de las regalías (25\% en 1620 y $19 \%$ en 1696) y de la imposición fiscal sobre el consumo y el comercio ( $29 \%$ en 1620 y $15 \%$ en 1696). El bovalar, la asegurada de la harina, la taberna y la panadería mantienen, incluso bajan, sus valores de arrendamiento durante el siglo XVII. La sisa sobre la carne y la treta, arbitrio indirecto sobre mercadurías, no elevan su rentabilidad hacendística pues entre 1620 y 1696 sus precios de arrendamiento se mueven entre márgenes mínimos.

Tanto los establecimientos y regalías como los impuestos indirectos sobre el consumo, deberían seguir una línea similar a la evolución demográfica de la comunidad, situación que en Petrer es divergente, pues el número de vecinos prácticamente se duplica entre 1611 y 1707 y las rentas de estos apartados hacendísticos se estancan. El autoconsumo local y familiar puede explicar esta menor participación porcentual a lo largo de la centuria de propios, regalías e impuestos indirectos. La tienda, sin embargo, es uno de los establecimientos para el 
abastecimiento de la comunidad rural que aumenta su valor de explotación. El arrendatario de la tienda tiene la obligación de abastecer diariamente a la población de arroz, tonyina, bacalao, sardinas, queso, jabón, aguardiente, tabaco, especias ... productos que a las familias de esta pequeña villa agraria no pueden obtener en el interior de su comunidad. Por tanto, una relativa autosuficiencia local de vino, harina y pan, carnes de ganado menor y de aves de corral, influirá en ciertas rentas hacendísticas.

De todos modos, no hay que sobrevalorar el autoconsumo local como factor de freno de los recursos de la hacienda municipal. Los resortes fiscales que utilizarán los regidores de la villa irán orientados hacia la imposición directa sobre rentas y patrimonios familiares, campo que permitirá una mayor flexibilidad y adaptación a las necesidades líquidas de la clavería para cubrir gastos esporádicos, o continuos ya durante la segunda mitad de s. XVII. La relativa autosuficiencia local, el reducido vecindario que permite mayor facilidad en la recaudación tributaria y el carácter poco oligárquico del gobierno municipal, hacen que las contribuciones directas tengan más protagonismo en las pequeñas villas, frente a los grandes núcleos urbanos donde las finanzas municipales se abastecen principaímente de sisas y monopolios.

La reorientación de la fiscalidad a lo largo de la centuria queda reflejada en la presión fiscal sobre el vecinđario de Petrer. El producto de sisas y treta arroja una media anual de 21 sueldos por vecino en la primera década de la repoblación, cantidad que baja a 12 sueldos en $1690^{5 s}$. Los repartimientos municipales directos invierten la curva de evolución, pues de 34 sueldos por vecino en 1620 se alcanzan los 47 sueldos en 1690. En global la presión fiscal aumenta levemente durante el s. XVII. El crecimiento demográfico permite una redistribución del gasto hacendístico que generan tachas y repartos directos. Por ejemplo los impuestos de la sal, del general del tall, de los soldats dels Estaments, o la renta señorial por el agua de Elda quedarán encabezadas en cuantías fijas para toda la villa durante la segunda mitad del s. XVII, por lo que la presión fiscal por vecino disminuirá.

Los repartos por obras públicas, pago de salarios, abono de intereses creditícios o solicitudes extraordinarias a la villa, hacen que la presión tributaria directa aumente. Cuando el gasto extraordinario excede de las posibilidades contributivas de los vecinos o coincide temporalmente con otras tributaciones directas ya existentes, los oficiales recurren al crédito para cubrir las necesidades monetarias. Este endeudamiento a cauda de un gasto conyuntural de envergadura repercute en la fiscalidad local a largo plazo, tal como ocurre con las pensiones de censales que anualmente debe responder la villa ante sus acreedores. Teóricamente, más de la mitad de la tributación directa que cada vecino aporta a las arcas municipales de Petrer responde al pago de intereses y capitales cređiticios. 


\section{NOTAS}

1.- Cfr. BERNABÉ GIL, D., Hacienda y mercado urbano en la Orihuela foral moderna. Alacant, 1989. CASEY, J., El Reino de Valencia en el s. XVII. Madrid, 1983; pp. 158-174. ALBEROLA ROMÁ, A., Jurisdicción y Propiedad de la tierra en Alicante (ss. XVII y XVIII). Alacant, 1984; PP. 128-141. FERRERO MICÓ, R., La hacienda municipal de Valencia durante el reinado de Carlos $V$. València, 1987. ANDRES ROBRES, F., Crédito y propiedad de la tierra en el Pais Valenciano (1600-1810). Valencia. 1987: pp. 33-66. PERIS ALBENTOSA, T., Propiedad y cambio social. Alzira (1465-1768). València, 1989; pp. 230-243. LA PARRA LÓPEZ, S., Los Borja y los moriscos. Repobladores y "terratenientes" en la Huerta de Gandía tras la expulsión de 1609. València, 1992.

2.- Véase el ejemplo de Gandía en LA PARRA LOPEZ, S., Op. Cit. pp. 198, 204, 212 y siguientes.

3.- Ibidem, pp. 39,220 y siguientes.

4.- (A)rchivo (M)unicipal de (P)etrer: Llibres de Clavería, 52/6.

5.- AMP: Llibres de Clavería, 52/3. En este año 1654 el precio del arrendamiento fue de 4 libras 10 sueldos.

6.- Tras la guerra sucesoria el nuevo ayuntamiento borbónico contará con un mayor patrimonio, formado a partir de las confiscaciones de bienes de los partidarios de la causa austracista. Según el Libro de Cabildos de 1712-1750 y las transmisiones reflejadas en la Giradora de 1682, hacia el año 1720 la villa posee como bines de propios 21 hectáreas de secano, 1 hectárea de regadío y varias casas de labranza.

7.- Sobre esta consideración de las regalías como impuestos indirectos simulados cfr. ANDRÉS ROBRES, F., Estructura y crisis de las finanzas municipales en el Castellón del Setecientos. Castellò, 1986; 994. Y BERNABÉ GIL, D., "La fiscalidad en los territorios peninsulares de la Corona de Aragón durante la época de los Austrias" en J.I. FORTEA y M.C. CREMADES (eds.). Politica y Hacienda en el Antiguo Régimen. Murcia, 1993; p. 26.

8.- Hay que tener presente que la mayoria de los vecinos de Petrer son agricultores, poseyendo casi siempre entre sus tenencias una o varias suertes de viña. Siguiendo la tradición de la comunidad morisca expulsada, durante los primeros años del asentamiento las nuevas familias cristianas transformarán la uva en pasas. Progresivamente la obtención de vino aumentará en detrimento de las pasas, que en el s. XVIII ya no son mencionadas en la documentación. Así, en el año 1627 hay tan sólo 18 cosecheros de vino que pagan a la Generalitat el impuesto que recae sobre este producto, y en el año 1642 ya hay 54 cosecheros, que a la vez duplican la producción (2.750 cántaros de vino). Cfr. PÉREZ MEDINA, T.V., La tierray la comunidad rural de Petrer en el siglo XVII. Alacant, 1995; pp. 94-96.

9.- Para la concordia de 1640 firmada entre el conde de Elda y la villa de Petrer, AMP: Llibres de Consells, 49/1 (24 de junio de 1640).

10.- AMP: Llibres de Claveria, 52/1 (ingresos de 1620). Ejemplos del derecho del conde de Elda sobre estas regalías son los permisos y licencias señoriales para el arrendamiento de las hierbas de los huertos en 1635, para el arrendamiento del bovalar en 1654 o para la ampliación de las tierras de la redonda del bovalar en 1660. AMP: Llibres de Consells, 49/1 (8 de abril de 1635); 49/2 (21 de junio de 1654 y 4 de febrero de 1660 ).

11.- Los ingresos hacendísticos por concepto de propios y regalias varia en cada localidad, según el grado de propiedad municipal y de administración directa de los establecimientos de producción y 
comercialización por el señor feudal. Cfr. ANDRÉS ROBRES, F., Crédito y propiedad ...; pp. 52-54.

12.- VILlalmanzo CAMENO, J., Catálogo de la documentación de la Real Cancillería del ARV. Alacant, 1984; p. 26 (documento 54).

13.- AMP: Llibres de Consells, 49/1 (24 de marzo de 1641).

14.- AMP: Llibres de Consells, 49/2. Tan sólo en el año 1633, como se observa en la Tabla VIl, ia sísa de la carne aumenta desmesuradamente. motivado por la prestación de 60 libras por parte de la villa al conde de Elda (AMP: Llibres de Consells, 49/1 - 11 de junio de 1633).

15.- Para Orihuela véase BERNABÉ GIL, D., Hacienda y mercado ...; p. 129 y passim. Para Gandia LA PARRA LÓPEZ, S., Op. Cit; p. 214. Para València BRINES BLASCO, J. y PÉREZ APARICIO, M.C., "Aproximació al sistema impositiu de la ciutat de València (segles XVI al XIX)" en Revista Afers, n" 4. Catarroja, 1986; p. 356. En Elda, localidad vecina de Petrer y señorio del mismo conde de Elda, la sisa sobre la carne es similar a la existente en Petrer: en 1703, por ejemplo, es de 4 dineros por libra de peso en Petrer y de 6 dineros en Elda (AMP: Llibres de Consells, 49/3 -26 de diciembre de 1703).

16.- Los datos de Orihuela en BERNABÉ GIL, D., Hacienda y mercado ...; p. 129. En la ciudad de València, en los primeros años del s. XVII, el precio de venta al púbico de la carne de moltó era de 60 dineros por libra de peso, de los que el $40 \%$ iban destinados a los caudales municipales. Cfr. BRINES BLASCO, J. y PÉREZ APARICIO, M.C., Op. Cit; p. 364.

17.- AMP: Llibres de Consells, 49/2 (12 de marzo de 1651).

18.- AMP. Llibres de Claveria, 52/6 (año 1690).

19.- En el año 1611 , año de la nueva carta puebla de Petrer, son establecidos 100 nuevos vecinos (425 habitantes) en sustitución de toda la población morisca precedente, y en 1696 ascienden a 216 vecinos (918 habitantes). Cfr. PÉREZ MEDINA, T.V., La tierra y la comunidad rural..., pp. 37-40.

20.- Cfr. Ihidem. pp. 62-67.

21.- AMP: Llibres de Claveria, 52/2, 52/3 y 52/4.

22.- AMP: Llibres de Claveria, 52/2 y 52/3. Una libra de peso equivale a 0.533 kilogramos.

23.- AMP: Llibres de Consells, 49/3 (11 de febrero de 1704).

24.- Archivo de Protocolos Notariales de Monòver (APNM): notario Baptiste Montesinos (acta del 5 de enero de 1696) y ARV: Real Audiencia: Escribanías de Cámara, año 1715, exp. 90.

25.- AMP: Llibres de Consells, 49/3 (3 de octubre de 1704, 5 de octubre de 1704 y 8 de noviembre de 1704).

26.- AMP: Llibres de Consells, 49/2 (18 de febrero de 1652 y 1 de abril de 1652). En Valencia la treta gravaba los productos que entraban en la ciudad con una tasa general del $5 \%$ hasta el año 1649 , duplicándose tras esta fecha. BRINES BLASCO, J. y PÉREZ APARICIO, M.C., Op. Cit.; p. 371.

27.- AMP: Liibres de Consells, $49 / 1$ ( 3 de abril de 1635 y 20 de julio de 1635).

28.- AMP: Llibres de Consells, 49/1 (22 de marzo de 1621). 
29.- AMP: Llibres de Consells, 49/1 (24 de marzo de 1641).

30.- AMP: Llibres de Consells, 49/2 (1 de abril de 1652). Suponemos que la sisa general sobre mercadurías -normal o doblada- no afectaba a los productos de obligado abastecimiento como son la carne, el vino de la taberna, el pan de la panadería, el trigo y la harina de la Asegurada y los múltiple productos contratados por el arrendatario de la tienda.

31.- AMP: Llibres de Consells, 49/1 (12 de febrero de 1617 y 22 de febrero de 1621 ).

32.- AMP: Llibres de Clavería, 52/3 (ingresos del año 1654).

33.- La importancia que adquiere la tributación directa en Petrer, lugar baronal, no es observada en importantes villas y ciudades. En Orihuela los ingresos por impuestos directos supone menos del $25 \%$ de las rentas ordinarias (BERNABÉ GIL, D.. Hacienda y mercado...; p. 117); en València no aparecen (BRINES BLASCO, J. y PÉREZ APARICIO, M.C., Op. Cit.); las contribuciones indirectas tienen primacía en Alzira (PERIS ALBENTOSA, T., Op. Cit; p. 280) y en Gandia ( LA PARRA LÓPEZ, S., Op. Cit; pp. 204-212); en Cocentaina hubo repartos directos frecuentes tras la expulsión morisca (PLA ALBEROLA, P., "Las finanzas municipales de Cocentaina ante la expulsión de los moriscos" en $/ /$ Jomades d'Estzdis Histórics Locals. Fiscalitat estatal i hisenda local (segles XVI-XIX). Palma de Mallorca, 1998; p. 76.

34.- AMP: Llibres de Consells, 49/3 (9 de agosto de 1705).

35.- AMP: Llibres de Consells, 49/3 (26 de julio de 1703).

36.- ARV: Real Audiencia: Procesos, Parte 1', letra C, exp. 793.

37.- AMP: Llibres de Consells, 49/1 (2 de febrero de 1617).

38.- AMP: Llibres de Consells, 49/3 (II de febrero de 1704).

39.- AMP: Llibres de Clavería, 52/4.

40.- AMP: Llibres de Consells, 49/3 (25 de agosto de 1701).

41.- AMP: Llibres de Consells, 49/1 (12 de febrero de 1617;26 de septiembre de 1640; 19 de octubre de $1642 ; 25$ de julio de 1645 ).

42.- Ver sobre este aspecto AMP: caja 37, exp. 20. En este expediente existe una hoja suelta con fecha de 1679 titulada "Conte de lo que se a de pagar les asiendes de la vila de Peirer per pencions que es dehuen dels sensals y la fira de cambi de les dossentes lliures", las cuales son repartidas proporcionalmente a las tierras irrigadas y a las tandas de agua.

43.- AMP: Llibres de Clavería, 52/4 (año 1676).

44.- AMP: Llibres de Consells, 49/2.

45.- AMP: Llibres de Consells, 49/1 (contrato de arrendamiento de la tacha de la sal del 16 de agosto de 1626).

46.- AMP: Llibres de Consells (31 de agosto de 1653).

47.- AMP: Llibres de Consells, 49/2 (17 de agosto de 1650 y 4 de junio de 1656). 
48.- AMP: Llibres de Consells, 49/2 (31 de agosto de 1653).

49.- GARCÍA SANZ, A., "EI Censal" en Boletín de la Sociedad Castellonense de Cultura, XXXVII (I96I). Castello, 1961; pp. $281-301$.

50.- AMP: Llibres de Consells, 49/I (8 de abril de 1635).

51.- AMP: Llibres de Consells, 49/2 (21 de octubre de 1656). Estas reconversiones de los canvis en censales también las nombra LA PARRA LÓPEZ, S., Op. Cit; pp. 222-224.

52.- El 5 de agosto de 1657 el consejo particular de Petrer trata sobre la demanda a la villa de las pensiones de un censal cargado en 1608, antes de la expulsión morisca (AMP: Llibres de Consells, 49/"). Tras la Guerra de Sucesión aparecen abundantes pleitos en la Real Audiencia valenciana iniciados por los acreedores (ARV: Real Audiencia: Escribanías de Cámara, año 1720, exp. 26 ...).

53.- La deuda también alimenta el propio endeudamiento. Así, por ejemplo, el 5 de febrero de 1682 Arnau de Barlonguera, carnicero de Petrer, presta al justicia y jurados de la villa de Petrer 50 libras para pagar rèditos censales, "per que encara que dita vila te forment no ya qui el compre" (APNM: notario Josep Gil, aก̃o 1682).

54.- AMP: Llibres de Consells, 49/1 (15 de agosto de 1618). El 7 de agosto de 1650 el consejo particular, ante el vencimiento de "les fires del cambi de Onil", acuerda "se fassen quadrelles y el que dega que pague" y "el jurat en cap recuerda que ya está la derrama para el cambi de Alacant y de Petrer" (AMP: Llibres de Consells, 49/").

55.- En los núcleos urbanos valencianos esta presión por sisas es mayor, alcanzando los 80-90 sueldos hacia mediados del s. XVII en Ontinyent y Orihuela. Ccr. BERNABÉ GIL, B., "La fiscalidad en los territorios peninsulares ...", pp. 30-31. 